\title{
Ethnocultural education in universities
}

\author{
Asil Salavatova ${ }^{1, *}$ \\ ${ }^{1}$ Nizhnevartovsk State University, 628600, Nizhnevartovsk, Russia
}

\begin{abstract}
The article describes the ethnocultural content of university education. Organizational and pedagogical conditions that have a positive impact on the development of interests, inclinations and abilities, ethno-pedagogical knowledge, ideas and traditions are described.
\end{abstract}

\section{Introduction}

Today, there is an urgent need to maintain the ethnic identity of peoples, protect and develop their national culture. In this regard, there is an increasing need to train highly qualified teachers who are able to combine national and multinational interests, respect and understand their ethnic culture, and culture of other nations. The solution to this problem depends on the level of formation of readiness of future teachers for professional activities.

\section{Materials and methods}

The issue of formation of ethnic cultural values as an important quality of students' personality is related to the formation of ethnic consciousness studied by a number of psychologists (I.S. Kon, A.N. Leontyev, D. B. Elkonin and others) and philosophers (E.A. Buller, N.A. Berdyaev, I.A. Ilyin, etc.). In their works, patterns and values of national culture, its influence on socio-cultural, economic, political processes in society were described.

Ethnopedagogical science developing pedagogical views of various ethnic groups investigated by $\mathrm{A}$. Disterweg [59], Ya.A. Komensky, K.D Ushinsky [163] and others, deals with theoretical and practical conceptual schemes for applying the experience of national education in modern conditions.

A significant role of folk pedagogy in the formation of readiness for ethnopedagogical activities is highlighted by V.F. Afanasyev, G.N. Volkov, L.A. Ibragimova, A.E. Izmailov, O.D. Mukaev, E.I. Sokolnikova, M.G. Taichinov, Y.I. Khanbikov et al.

Due to the aggravation of ethnic problems, there is a tendency to actualize ethnic problems of education. A large number of researchers study traditional pedagogical culture of individual ethnic groups: Sh.M.Kh. Arsaliev (Chechnya); V.F. Afanasyev (Siberia and the Far East); A.L. Bugaev, L.A. Ibragimova, S.M. Malinovskaya (peoples of the North); A.G. Bulatova (Dagestan); L.D. Vavilova (Komi); ME AND.
Khanbikov (Tatarstan); G.N. Volkov, E.I. Sokolnikov (Chuvashia); A.Sh. Gashimov (Azerbaijan); A.E. Izmailov (Central Asia and Kazakhstan); O.D. Mukaev (Kalmykia); A.I. Nikolaev (Russia-Russian); K.A. Pirliev (Turkmenistan); I.A. Shorov (Adygea); S.A. Shaals (Tuva); IN AND. Elashvili (Georgia) and others.

Training students for schools with an ethnocultural content of education requires diagnostic materials, justification of pedagogical conditions, and didactic tools.

The ethnocultural content of education is based on foundations of popular pedagogy, cultural studies, philosophy, the theory of socio-cultural activities, ethnopsychology, ethnology and other related branches enriching modern pedagogical experience. The ethnocultural content of education requires a multicultural and multinational system of training and education.

In the modern educational space, a combination of national interests and rights of citizens is required; the formation of priority tasks should be aimed at preserving the ethno-cultural, linguistic and religious affiliation. After all, material and spiritual culture is based on the experience of generations.

\section{Main body}

The interaction of folk (ethnic) pedagogy and public education can be traced in the creative heritage of Jan Amos Comenius. All his activities [1] was determined by the desire to help his people in their quest for a brighter future. He studied the life of the people, wrote its history, explored geography, developed a map of the Motherland, collected Czech folk proverbs: "The wisdom of the ancestors is a mirror for posterity." The great humanist educator wanted teachers to be truly folk. The first and main requirement for them is to learn, love their native language, oral creativity of the people. Comenius proved that only the people who know and love their mother tongue love other nations.

The great Russian teacher K.D. Ushinsky threw a bridge from pedagogy of Y.A. Comenius to the latest

\footnotetext{
${ }^{*}$ Corresponding author: asil-06@list.ru
} 
pedagogical searches of the second half of the XIX and early XX centuries. Developing the experience of Y.A. Comenius, he applied it in the spiritual rallying of the peoples of Russia. K.D. Ushinsky believed that the education system is generated by the history of the people, their needs and life, their material and spiritual culture [2].

Reliance on perfect knowledge of the essential features of the spiritual life of many peoples is one of the fundamental principles of the pedagogical system, free from national narrow-mindedness and having enormous attractive power.

In our study, we rely on the ideas of folk pedagogy and possibilities of their use in ethnocultural education. According to Ya.I. Khanbikova, attention should be paid to the tasks of folk pedagogy, i.e. the development of skills and interaction between processes of education and training: "Folk pedagogy refers to the field of folk empirical knowledge, which expresses goals and objectives of upbringing, combination of folk remedies, skills and abilities of upbringing and training" [3].

Ethnocultural education is a holistic process of studying and practical development of ethnocultural heritage, formation and upbringing of an individual based on the traditions of ethnic culture, combining the mono-ethnic depth of comprehension of native culture and multi-ethnic width [4].

The ideology of the ethnocultural content of education is realized through the ethnocultural component of education. In the scientific, methodological and pedagogical literature, the term "ethnocultural component of education" is often found. The most common definition of this concept is as follows: the ethnocultural component is everything that contributes to the development of the creative abilities, gives a more complete picture of the richness of national culture, the way of life of the people, their history, language, literature, spiritual goals and values, which contributes to the development of a harmonious personality, a patriot, a tolerant person. The ways to implement the ethnocultural component is to adjust the curricula, develop and implement pedagogical technologies that reflect directions of schools with the ethnocultural Russian component.

The purpose of ethnocultural education is formation of value orientations on the basis of ethnocultural ideas that promote self-identification and tolerance towards other cultures. Consequently, the content of ethnocultural education is a system of knowledge of national-cultural and socio-historical values that reflect the nature and psychological characteristics, identity of a nation and its culture, as well as knowledge and ethnocultural achievements of other peoples, abilities and skills to use them [5].

The purpose of ethnocultural education is to compensate for ethnocultural educational needs of the indigenous peoples of the North, develop an ethnocultural identity, prepare students for life in both traditional and modern communities.

Ethnocultural education described in textbooks, programs, curricula, anthologies, methodological and reference books, is aimed at combining history and culture of the Ugra region, a generally accepted way of life and adaptation to a civilized society. This combination is aimed at compensating for the loss of spiritual wealth accumulated by the Northern peoples during the centuries. Education of the Khanty and Mansi peoples reflects the experience of the traditional life of ethnic groups, influencing an understanding of the world, thinking, ethnopedagogical ideals.

The problem of training teachers for schools with an ethnocultural content of education is acute. Without its solution, it will be difficult to solve economic, social, legal and other issues that arise before the representatives of the Northern peoples during the transition to market relations. The main task is to develop a balanced policy for the training of qualified personnel in accordance with the needs of production and social sectors. At the same time, it is quite obvious that maintenance of ethnic traditions of educational institutions is impossible without a teacher who is ready to implement the ethnocultural content of education and aware of the importance of this activity. Teachers capable of solving relevant ethnic problems are required.

One of the forms of revival of spirituality of the Khanty and Mansi ethnos is ethnopedagogization, covering the entire system of education. If education is defined as preservation, improvement and transfer of spiritual values from one generation to another, the entire educational system must be penetrated by folk pedagogy.

Pedagogical aspects of readiness formation do not disregard this category in scientific research on pedagogy. The readiness of a teacher for professional and pedagogical activities should be combined with theoretical, practical, and psychological types of readiness.

When developing the readiness of students for pedagogical activities, most researchers focus on the formation of professional knowledge, development of pedagogical skills, and personality traits. Readiness for pedagogical activities is the main condition for effective professional activities.

The student's readiness for pedagogical activities is an important professional quality and a complex psychological system which includes: a) a positive attitude to the profession, stable motives; b) adequate requirements for personality traits, abilities, temperament; c) knowledge, skills, and abilities; d) perception, memory, attention, thinking, emotional, volitional processes, etc. [6].

Activities of students are aimed at mastering sources of scientific, cultural and professional information, universal ways of practical and theoretical educational activities; ways of designing and implementing a psychological and pedagogical support; ways of research. Schools need teachers with a developed professional readiness [7].

A student becomes socially active if he is prepared for this work, i.e. he knows the content of ethnopedagogy, the methodology of its teaching, introducing its ideas into school practice. Integrated cyclical courses are required.

The process of training students for professional activities in schools with an ethnocultural content of 
education is part of a complex system of general professional pedagogical training characterized by changing levels of development and influenced by premises and pedagogical conditions. The formation of students' readiness for professional activities is a dynamic process aimed at developing professional qualities with a pronounced personality component. The effectiveness of the formation of students' readiness for professional activities depends on the following conditions: a psychologically sound choice of profession, professional selection, a developing nature of professional educational process, consistent development of a system of interrelated activities.

Young people are susceptible to various types of negative social trends [8].

Professional readiness to work in schools with an ethnocultural content is a complex dynamic process whose core is an understanding of the significance of this activity, formation of a national identity, ethnopedagogical culture and professional traits.

Universities should train students who are able to work in the conditions of ethnocultural specificity. There are textbooks on ethnopedagogy which reflect many aspects of history, culture, and traditions of the peoples inhabiting a particular ethnic region. Despite the fact that in schools with an ethnocultural orientation, folklore, history of peoples, and national etiquette are studied, the further development of these courses is required.

The readiness for pedagogical activities has an invariant component containing the training result and requirements for the implementation of pedagogical activities.

The process of readiness development is carried out in the general context of the educational process integrating all possible pedagogical influences on students.

The analysis of research approaches makes it possible to single out knowledge, skills, experience of their application in practice, positive attitudes of students to the teaching profession, sustainable motives for teaching, and the presence of professional personality traits in the readiness structure. The main components are as follows: motivational, substantive, operational, and reflective.

We assume that the formation of all interconnected and interdependent components of readiness should be carried out through the implementation of pedagogical conditions:

- updating the content of academic disciplines studying students' readiness for professional activities in schools with an ethnocultural content of education;

- implementation of the elective training course for students "Folk pedagogy of the Khanty and Mansi";

- independent work of students on ethnic culture and ethnopedagogy of the Khanty and Mansi;

- extracurricular ethnocultural and ethnopedagogical activities of students together with children, parents and teachers;

- cultural activities of students;

- teaching practice in schools with an ethnocultural component;

- research activities;
- monitoring of the readiness development.

\section{Control experiment results}

At the control stage of the experimental work, the final diagnosis of the level of students' readiness for professional activities was carried out. We evaluated the effectiveness of the model, organizational and pedagogical conditions, analyzed and compared the ascertaining and control levels of students' readiness for professional activities in schools with an ethnocultural content. We carried out a diagnostic study on all the indicators and compared the results with those obtained at the ascertaining stage. The experiment involved 124 students. At the formative stage, 59 people took part.

Assessing the first component of students' readiness, we repeated diagnostic procedures for assessing motives, values, and identities of students in both groups.

The analysis of the data allowed us to obtain the following results (Table 1).

Table 1. Levels of students' readiness to implement the ethnocultural content by each criterion (\%)

\begin{tabular}{|l|c|c|c|}
\hline \multicolumn{1}{|c|}{ Readiness criteria } & \multicolumn{3}{c|}{ The control stage of the experiment } \\
\hline Levels of development & High & Medium & Low \\
\hline Motivational value & 38 & 55.8 & 6.2 \\
\hline Substantial & 83 & 17 & - \\
\hline Active & 52.5 & 35.6 & 11.9 \\
\hline Personal development & 41 & 37 & 22 \\
\hline Generalized indicator & 54 & 36 & 10 \\
\hline
\end{tabular}

Figure 1 shows the comparative results of the ascertaining and control stages of the pedagogical experiment.

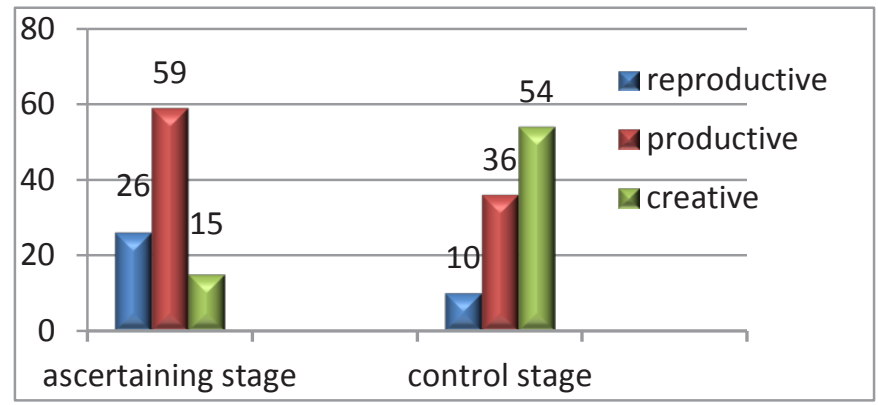

Fig. 1. Comparative results of the pedagogical experiment

The generalized indicator determined by the method of mathematical data processing allows us to assess the levels of students' readiness to implement an ethnocultural content in secondary schools.

Purpose of $\chi 2$ criterion - Pearson criterion (Table 2)

We performed:

1. Calculation of theoretical frequency $(f \mathrm{~T})$.

2. Calculation of the difference between empirical and theoretical frequencies by each category.

3. Calculation of the degrees of freedom. We 
introduced a correction for continuity (if $\mathrm{v}=1$ ).

4. The resulting differences were squared.

5. The resulting squares of the differences were divided by theoretical frequency (the last column). The sum is $\chi 2 \mathrm{emp}$.

Table 2. Purpose of $\chi^{2}$ criterion - Pearson criterion

\begin{tabular}{|l|c|c|c|c|c|}
\hline No. & $\begin{array}{c}\text { Empirical } \\
\text { frequency }\end{array}$ & $\begin{array}{c}\text { Theoretical } \\
\text { frequency }\end{array}$ & $\begin{array}{c}(\boldsymbol{f} \text { Э } \\
-\end{array}$ & $\begin{array}{c}\boldsymbol{f} \mathbf{T}) \\
(\boldsymbol{f} \text { Э } \mathbf{T}) \mathbf{2}\end{array}$ & $\begin{array}{c}\boldsymbol{f} \text { T } \mathbf{T} \text { ) } \\
/ \boldsymbol{f} \mathbf{T}\end{array}$ \\
\hline 1 & 25 & 17.5 & 7.5 & 56.25 & 3.214 \\
\hline 2 & 10 & 17.5 & -7.5 & 56.25 & 3.214 \\
\hline 3 & 60 & 48 & 12 & 144 & 3 \\
\hline 4 & 36 & 48 & -12 & 144 & 3 \\
\hline 5 & 15 & 34.5 & - & 380.25 & 11.022 \\
\hline 6 & 54 & 34.5 & 19.5 & 380.25 & 11.022 \\
\hline Total & 200 & 200 & - & - & 34.472 \\
\hline
\end{tabular}

Result: $\chi_{\text {emp }}^{2}=\mathbf{3 4 . 4 7 2}$

Critical values of $\chi 2$ at $v=2$

\begin{tabular}{|c|c|c|}
\hline \multirow{2}{*}{$\mathrm{V}$} & \multicolumn{2}{|c|}{$\mathrm{p}$} \\
\cline { 2 - 3 } & 0.05 & 0.01 \\
\hline 2 & 5.991 & 9.21 \\
\hline
\end{tabular}

Differences between two distributions can be significant if $\chi 2 \mathrm{emp}$ дis equal to or exceeds $\chi 20.05$, and more significant if $\chi 2 \mathrm{emp}$ is equal to or exceeds $\chi 20.01$.

Response: $\chi 2 \mathrm{emp}$ is equal to the critical value or exceeds it of differences between the distributions are significant (hypothesis H1).

In testing the model and organizational and pedagogical conditions for students' readiness development, we obtained results confirming the effectiveness of the pedagogical impact. At the control stage, $54 \%$ of students (the generalized indicator with a high level) showed a creative level of readiness for the implementation of an ethnocultural content; while at the ascertaining stage, thee share was $15 \%$.

$36 \%$ of students had a productive level of readiness. Only $10 \%$ of students showed a reproductive level which manifests itself in the orientation on the subject side of the profession.

Thus, we can conclude about the effectiveness of the model and reasonable organizational and pedagogical conditions, and emphasize the need for developing students' readiness for professional activities in schools with an ethnocultural content of education.

The control indicators show that the formation of a readiness for professional activities in schools with an ethnocultural content of education had a positive impact on the development of interests, inclinations and abilities of students.

\section{Conclusion}

The ethnocultural content of education is based on the combination of the cultural and educational space, equality, preservation and development of languages of the peoples inhabiting the territory of the district. It is aimed at protecting and developing culture and traditions of the indigenous peoples of the North (Khanty, Mansi, Nenets). The purpose of the ethnocultural content of education is to compensate for ethnocultural educational needs of the small peoples of the North, to form and correlate ethnocultural identity of students, prepare them for life in traditional and modern society. The main tasks of the ethnocultural education are preservation and development of ethnic identity, languages; deepening of knowledge and ideas about national culture; expansion of knowledge about the way of life, history, literature, spiritual values.

The readiness of students for professional activities in schools with an ethnocultural content of education is considered as an integrative quality which is manifested in ideas, values, knowledge about ethnoculture, its place in Russian and world culture, ethnocultural tolerant interaction. Willingness can be considered as a qualitative, systemic, dynamic state of a personality including motivational, substantive, creative, and reflective indicators. Readiness as a structurally meaningful personal quality can have an invariant or variable content.

The development of readiness for professional activities in schools with an ethnocultural content seems to be a complex process that encompasses all meaningful components of the educational process. The organization of an ethno-pedagogically oriented educational process has been tested using a model that includes the following elements: social order, purpose, readiness components, organizational and pedagogical conditions, criteria, levels of formation, result.

The following organizational and pedagogical conditions contribute to the effectiveness of students' readiness development:

- updating the content of academic disciplines studying students' readiness for professional activities in schools with an ethnocultural content of education;

- implementation of the elective training course for students "Folk pedagogy of the Khanty and Mansi";

- independent work of students on ethnic culture and ethnopedagogy of the Khanty and Mansi;

- extracurricular ethnocultural and ethnopedagogical activities of students together with children, parents and teachers;

- cultural activities of students;

- teaching practice in schools with an ethnocultural component;

- research activities;

- monitoring of the readiness development.

\section{References:}

1. J.A. Komensky. Selected works. In 2 volumes. Maternal School or on the caring upbringing of youth during their first six years 1, 210, (M .: Pedagogy, 1982)

2. G.I. Baturina, T.F. Kuzina Folk pedagogy in the modern educational process: a manual for teachers, educators and methodologists, 141 (M: School Press, 2003) 
3. Ya.I. Khanbikov From the History of the Pedagogical Thought of the Tatar People, 232, (Kazan: Tatknigoizdat, 1967)

4. A.B. Afanasyeva Knowledge. Understanding. Skill Ethno-cultural education: essence, content structure, problems of improvement, 3, 189-195 (M., 2009).

5. E.N. Chenkuraeva. Pedagogical conditions for ethnocultural education in an innovative ionic educational institution: Thesis, 22. (Volgograd, 2007).

6. M.I Dyachenko, L. A Kandybovich. Psychology of Higher Education 383 (Minsk: BSU, 1981).
7. V.M. Yangirova, Formation of research competencies for bachelors of pedagogy, 143 (Ufa: BSPU, 2009).

8. E. Bauer, A. Salavatova., R Shikhaliyev. The Educational Environment of the University as a Means of Preventing the Ideology of Extremism Among Young People. Advances in Social Science, Education and Humanities Research, 288, 216-219. (2018). 